\title{
Fuzzy Gain Scheduling of PID (FGS-PID) for Speed Control Three Phase Induction Motor Based on Indirect Field Oriented Control (IFOC)
}

\author{
Indra Ferdiansyah, Era Purwanto, Novie Ayub Windarko \\ Politeknik Elektronika Negeri Surabaya \\ Kampus PENS, Jl. Raya ITS, Sukolilo Surabaya \\ indraferdiansyah@pasca.student.pens.ac.id, \{era,ayub\}@pens.ac.id
}

\begin{abstract}
This paper propose about using PID control system based on $\mathrm{Kp}, \mathrm{Ki}$, and Kd parameter determination with scheduling process from fuzzy logic. Control system is used to arrange speed of three phase induction motor using IFOC method. This method can be minimized the main problem from speed control of induction motor which is a transient condition. The robustness validation from this system use testing process of dynamic speed which is compared with the other control system to know the system performance in transient condition such as (rise time, overshoot, undershoot and settling time). The result shows using the proposed system has better performance responses which is requiring 0.001 seconds time in transient condition up to steady state condition without overshoot and undershoot problem.
\end{abstract}

Keywords: PID, Fuzzy scheduling, IFOC, Induction Motor, and Performance Control.

\section{INTRODUCTION}

Nowadays, like a consequence of the important progress in the power electronics and of microcomputing, the control of the AC electric machines known a considerable development and a possibility of the real time implantation applications. It is widely recognized that the induction motor is going to be the main actuator for industrial purposes [1], [2]. Indeed, as compared to the DC machine, it provides a better power or mass ratio, a simpler maintenance and relatively lower cost. However, it is traditionally for a long time, used in industrial applications that do not require high performances, this because its control is a more complex problem, its high nonlinearity and its high coupled structure. Furthermore, the motor parameters are time-varying during the normal operation and most of the state variables are not measurable. On the other hand, the direct current 
(D.C) machine was largely used in the field of the variable speed applications, where torque and flux are naturally decoupled and can be controlled independently by the torque producing current and the flux producing current. Since Blashke and Hasse have developed the new technique known as vector control [1-4], the use of the induction machine becomes more and more frequent. This control strategy can provide the same performance as achieved from a separately excited DC machine, and is proven to be well adapted to all type of electrical drives associated with induction machines[5].The vector control technique has been widely used when high performance rotary machine drive is required, especially the Indirect Field Oriented Control (IFOC) that is the most effective vector control of three phase induction motor due to the simplicity of designing and implementation [6]. Decoupled torque and flux control in IFOC of induction machines permits higy dynamic response. While, induction motor control cann't apart from its previous condition. The real nonlinear characteristic from motor and the modification parameter from control caused to the modification value in control process when the time of trancient condition was toward to the steady state in set point achievement. Using appropriate control system can be minimized its problem.

The most widely used controller in the industrial applications is the PIDtype controllers because of their simple structures and good performances in a wide range of operating conditions [7]. In the literature, the PID controllers can be divided into two main parts: In the first part, the controller parameters are fixed during control operation. These parameters are selected in an optimal way by known methods such as the Zeigler and Nichols, poles assignment...etc. The PID controllers of this part are simple but cannot always effectively control systems with changing parameters or have a strong nonlinearity; and may need frequent on-line retuning [8]. In the second part, the controllers have an identical structure to PID controllers but their parameters are tuned on-line based on parameters estimation of the process. Such controllers are known as adaptive PID controllers [2].

The application of knowledge-based systems in process control is growing, especially in the field of fuzzy control [9-12]. In fuzzy control, linguistic descriptions of human expertise in controlling a process are represented as fuzzy rules or relations. This knowledge base is used by an inference mechanism, in conjunction with some knowledge of the states of the process (say, of measured response variables) in order to determine con trol actions. Although they do not have an apparent structure of PID controllers, fuzzy logic controllers may be considered nonlinear PID controllers whose parameters can be determined on-line based on the error signal and their time derivative or difference [11].

This paper proposedthe application FGS-PID for speed control of three phase induction motor based on IFOC. The new scheme utilizes fuzzy rules and reasoning to determine the controller parameters, and the PID controller generates the control signal for the process on IFOC systems.It is 
demonstrated in this paper that human expertise on PID gain scheduling can be represented in fuzzy rules. Furthermore, better control performance can be expected in the proposed method than that of the PID controllers with fixed parameters on dynamic conditions. The investigation of transient condition (involve rise time, overshoot, undershoot, and settling time) in speed of dynamic is presented section 2. The comparation between FGS-PID and other control is presented section 3.

\section{RELATED WORKS}

The theory of Fuzzy Gain Scheduling-PIDwas firstly developed by ZhenYu Zhao, Masayoshi Tomizuka, and Satoru Isaka in 1993.UsingFuzzy gain scheduling could be used to determine gain parameters of PID control.PID is one of popular control in industrial because it has simple design,robust control andalso easy to be implemented. However, parameter of gain PID is difficult to be determined which needs re-tuning to get a good result. One of developed tuning methodsis Ziegler Nichols that is simple indetermining ofKp gain, Ki, and Kd of PID parameters [7].

Fuzzy logic was presented by Prof. L.Zadeh in 1965 from California University. Fuzzy logic was founded after crips logic method. The value of crips logic is true " 1 "or false " 0 ". Fuzzy logic has uncertain value between true and false. Fuzzy logic allows membership value between 0 and 1 and also several variables that are expressed in linguistic language such as positive, zero, and negative.The principle of FGS-PID is using two inputs (error and $\Delta$-error) with output fuzzy kp', kd', and $\alpha$. Fuzzy kp' is used to schedule parameter gain (p), $\mathrm{kd}$ ' is used to schedule parameter gain ( $\mathrm{Td}$ ), and $\alpha$ is used to schedule gain (Ti).By applying gain system scheduling of PID parameter, PID tuning process is easier to do in stabil or unstabil condition. In Zhao and friends' presentation, also comparing the output response system of FGS-PID control, PID-ZN, and Kitamori. Thecomparations are done from output control system for second, third, and fourth order. The result shows that FGS-PID has more optimal response because it can reduce overshoot condition and osilationsystem[13].

Then, Bousserhane presents optimal fuzzy gains scheduling of pi controller for induction motor speed control. To overcome the disadvantages of PID controllers and FLC, we propose in this paper a combination between them together. PID parameters controller can be tuned on-line by an adaptive mechanism based on a fuzzy logic for induction machine speed control. Design of an optimal fuzzy gain scheduling of PI controller combines the merits of the sliding mode control and the fuzzy inference mechanism is proposed. A fuzzy gain scheduling of conventional PI controller is investigated, in which the fuzzy logic system is used on-line to generate the PI controller parameters [2].

In this paper, it will be proposeddesign about speed control of threepahse induction motor based on IFOC with combining PID controller and Fuzzy as gain scheduling parameter of $\mathrm{kp}$, ki, and kd that can simplify the 
tuning process of PID control to get a better response result in transient condition at speed of dynamic.

\section{ORIGINALITY}

The constribution of this paper is to implement speed control of induction motor based on PID with scheduling and reasoning from fuzzy logic control to obtain parameter system which is suitable with determined condition using IFOC method. Using the proposed method can be minimized the problem of induction motor rotation in transient condition which has non-linear characteristic. The principle of fuzzy gain scheduling is used to arrange the PID gain that is appropriate with the declared condition. The output of control system is control signal which is used for IFOC system in control of induction motor system. The implementation of proposed IFOC method is simply to apply which is using control system based on vector technique. The vector technique is oriented to the field control which can be controlled the torque unit and flux separately. This system is usually called by decoupled system. the modification of flux and torque can be influenced to the motor rotation which is represented as current and speed modification.

The parameter modification from control system can be decreased the performance of control system which is showed from motor responses in transient condition. Using FGS-PID is one of solution to minimize this problem. The control design is arranged for $0-1000$ Rpm speed which can be given the better result in modification parameter condition. Verification process and the robustness test of this sytem is used dynamic speed control sytem which is observed in transient condition involve rise time, overshoot, undershoot and time settling.

\section{SYSTEM DESIGN}

\subsection{RESEARCH METHOD}

\subsubsection{PID Controller}

PID control is a combination from three methods; those are proportional control, integral, and derivative. Combination of these methods can be used to minimize disadvantage of each controls. Proportional control (P) has function to accelerate up to set point condition, but it can cause overshoot. Disadvantage of control (P) can be solved by adding integral control (I) that functions to reduce overshoot, but system will be slow. So it needs derivative control (D) to accelerate system. But sometimes, it causes osilation condition before getting steady state. The equation of PID control is given to this following equation [13]:

$$
u(t)=K p e(t)+K i \int_{0}^{t} e(t)+K d \frac{d}{d t} e(t)
$$




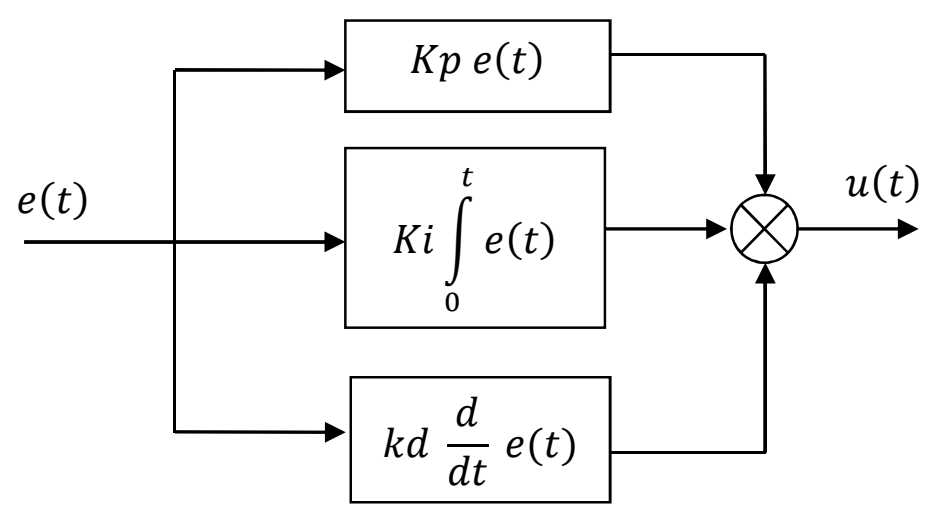

Figure 1. Blok of diagram PID controller

PID control has gain parameters that can be influencedto the control; those are $\mathrm{Kp}, \mathrm{Ki}$, and $\mathrm{Kd}$. The values of gains can be used to get a good control result. However, it is difficult to be determined that needs re-tuning to get a good result. Ziegler-Nichols(ZN) method is one solution to determine a difficult a gain value of good control. This method also can be used for tuning process.

$\mathrm{ZN}$ is one of tuning method that is used for deciding PID parameters. First tuning process is setting Kp, and then set the value of Ti to be unlimited, and set the value of Td to be zero. Then, increase the value of Kp until the value of oscillation and amplitude are the same. Gain that creates oscillation condition is gain $K u$ and oscillation period of full wave is $P u$. The value of $K u$ and $P u$ are used for getting the value of $K p, K i$, and $K d$. ZN tuning rule is shown in table 1 [13].

Table 1. Rule of Ziegler-Nichols Method

\begin{tabular}{|l|l|c|l|}
\hline Type of Controller & \multicolumn{1}{|c|}{$\boldsymbol{K}_{\boldsymbol{p}}$} & $\boldsymbol{T}_{\boldsymbol{i}}$ & $\boldsymbol{T}_{\boldsymbol{d}}$ \\
\hline Proportional (P) & $0.5 \mathrm{Ku}$ & - & - \\
\hline $\begin{array}{l}\text { Proportional Integral } \\
\text { (PI) }\end{array}$ & $0.45 K u$ & $\frac{P u}{1.2}$ & - \\
\hline $\begin{array}{l}\text { Proportional Integral } \\
\text { Derivative (PID) }\end{array}$ & $0.6 K u$ & $\frac{P u}{2}$ & $\frac{P u}{8}$ \\
\hline
\end{tabular}

\subsubsection{Fuzzy gain scheduling-PID}

On the Fig 2 shows the PID control system with a fuzzy gain scheduler. The approach taken here is to exploit fuzzy rules and reasoning to generate controller parameters. 


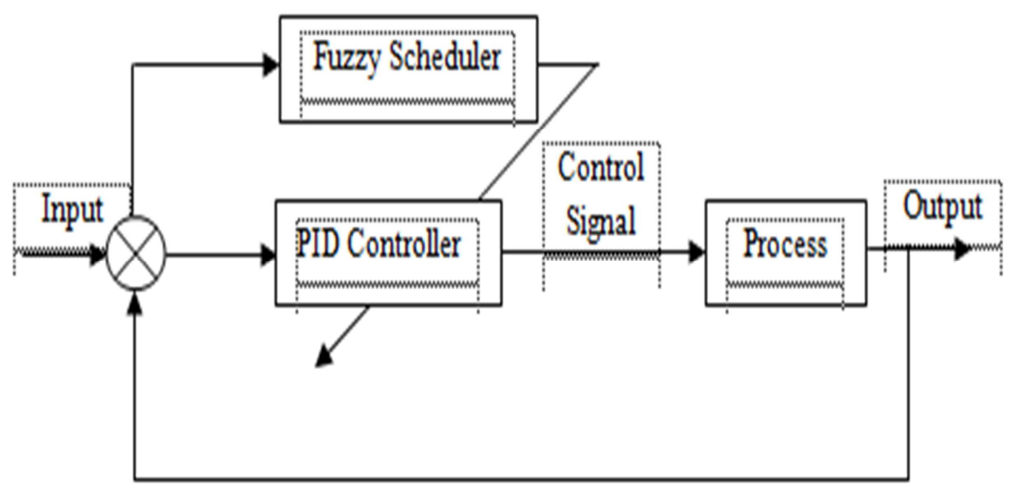

Figure 2.Blok of diagram FGS-PID controller

It is assumed that $\mathrm{Kp}$ are in prescribed ranges [Kp min, Kp max] and [Kd min, Kd max] respectively. The apropriate ranges are determined experimentally and will be given in equation (4). For convenience, Kp and $\mathrm{Kd}$ are normalized into the range between zero and one by the following linear transformation [7]:

$$
\begin{aligned}
& K_{p}^{\prime}=\left(K_{p}-K_{p \min }\right) /\left(K_{p \max }-K_{p \min }\right) \\
& K_{d}{ }^{\prime}=\left(K_{d}-K_{d \min }\right) /\left(K_{d \max }-K_{d \min }\right)
\end{aligned}
$$

In the proposed scheme, PID parameters are determined based on the current error $\mathrm{e}(\mathrm{k})$ and its first difference $\mathrm{Ae}(\mathrm{k})$. The integral time constant is determined with reference to the derivative time constant and the integral gain is thus obtained by

$$
K_{i}=K_{p} /\left(\alpha T_{d}\right)=K_{p}^{2} /\left(\alpha K_{d}\right)
$$

The parameters $K_{p}{ }^{\prime}, K_{d}^{\prime}, \alpha$ are determined by a set of fuzzy rules of the form. The membership functions (MF) of these fuzzy sets for error [e (k)] and delta error $[\Delta \mathrm{e}(\mathrm{k})]$ are shown in Fig. 3. In this figure, $\mathrm{N}$ represents negative, $\mathrm{P}$ positive, ZO approximately zero, S small, M medium, B big. Thus NM stands for negative-medium, PB for positive big, and so on.

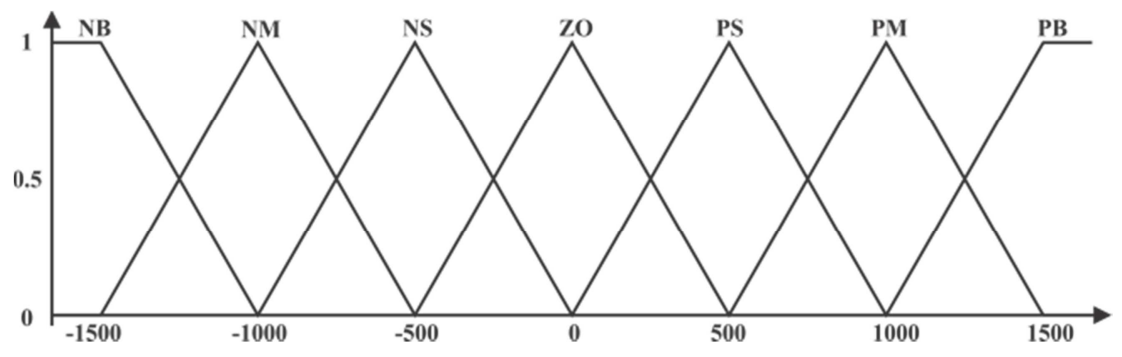

Figure 3. Membership function error and $\Delta$ error 


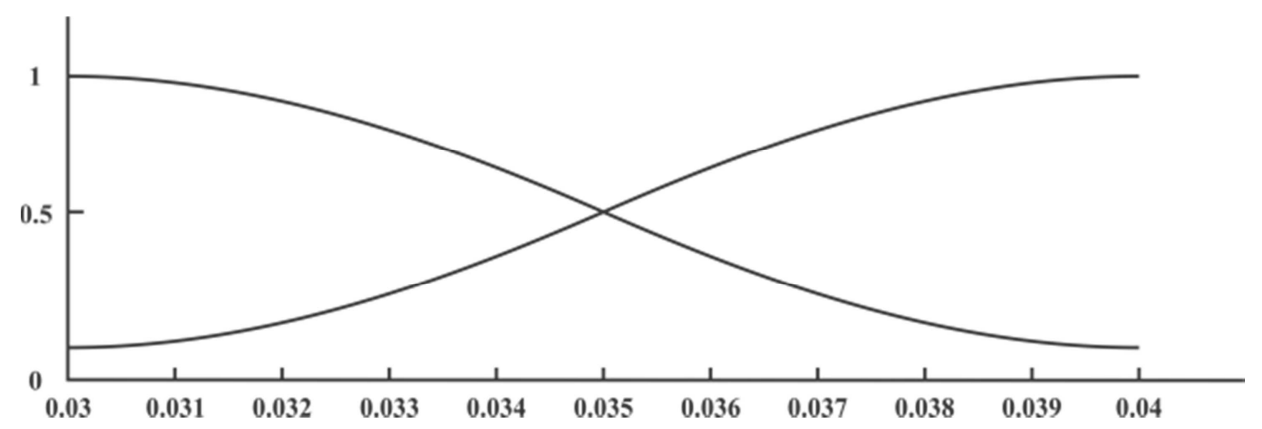

Figure 4. Membership function for Kp' and $\mathrm{Kd}$ '

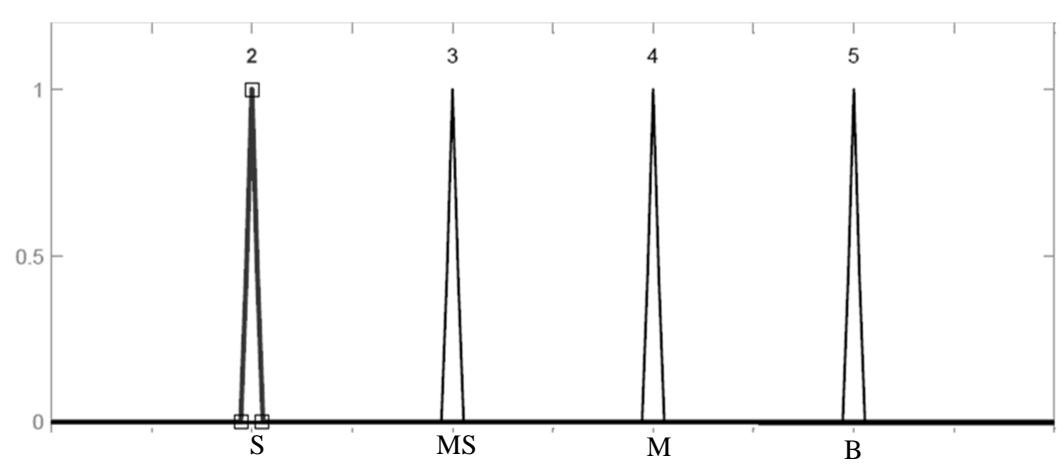

Figure 5. Output of Membership function $\alpha$

The rule base of Fuzzy gain scheduler to deremine PID parameter shown in table 2,3 , and 4 [2].

Table 2. Fuzzy tuning rule for kp'

\begin{tabular}{|c|c|c|c|c|c|c|c|c|}
\hline & \multicolumn{7}{|c|}{$\Delta$ error } \\
\hline & & NB & NM & NS & ZO & PS & PM & PB \\
\hline \multirow{7}{*}{$\begin{array}{l}\mathbf{e} \\
\mathbf{r} \\
\mathbf{r} \\
\mathbf{0} \\
\mathbf{r}\end{array}$} & NB & B & B & B & B & B & B & B \\
\hline & NM & $S$ & B & B & B & B & B & $S$ \\
\hline & NS & $S$ & $S$ & B & B & B & $\mathrm{S}$ & $\mathrm{S}$ \\
\hline & ZO & $S$ & $S$ & $S$ & B & S & S & $S$ \\
\hline & PS & $\mathrm{S}$ & $\mathrm{S}$ & B & B & B & $\mathrm{S}$ & $\mathrm{S}$ \\
\hline & PM & $\mathrm{S}$ & B & B & B & B & B & $S$ \\
\hline & PB & B & B & B & B & B & B & B \\
\hline
\end{tabular}


Table 3. Fuzzy tuning rule for kd'

\begin{tabular}{|c|c|c|c|c|c|c|c|c|}
\hline & \multicolumn{7}{|c|}{$\Delta$ error } \\
\hline & & NB & NM & NS & ZO & PS & PM & PB \\
\hline \multirow{7}{*}{$\begin{array}{l}\mathbf{e} \\
\mathbf{r} \\
\mathbf{r} \\
\mathbf{0} \\
\mathbf{r}\end{array}$} & NB & $S$ & $S$ & $S$ & $S$ & $S$ & $\mathrm{~S}$ & $S$ \\
\hline & NM & B & B & $S$ & $S$ & $S$ & B & B \\
\hline & NS & B & B & B & $S$ & B & B & B \\
\hline & ZO & B & B & B & B & B & B & B \\
\hline & PS & B & B & B & $S$ & B & B & B \\
\hline & PM & $B$ & $B$ & $S$ & $S$ & $S$ & B & B \\
\hline & PB & $S$ & $S$ & $S$ & S & $S$ & S & $S$ \\
\hline
\end{tabular}

Table 4. Fuzzy tuning rule for $\alpha$

\begin{tabular}{|c|c|c|c|c|c|c|c|c|}
\hline & \multicolumn{7}{|c|}{$\Delta$ error } \\
\hline & & NB & NM & NS & ZO & PS & PM & PB \\
\hline \multirow{7}{*}{$\begin{array}{l}\mathbf{e} \\
\mathbf{r} \\
\mathbf{r} \\
\mathbf{0} \\
\mathbf{r}\end{array}$} & NB & 2 & 2 & 2 & 2 & 2 & 2 & 2 \\
\hline & NM & 3 & 3 & 2 & 2 & 2 & 3 & 3 \\
\hline & NS & 4 & 3 & 3 & 2 & 3 & 3 & 4 \\
\hline & $\mathbf{Z O}$ & 5 & 4 & 3 & 3 & 3 & 4 & 5 \\
\hline & PS & 4 & 3 & 3 & 2 & 3 & 3 & 4 \\
\hline & PM & 3 & 3 & 2 & 2 & 2 & 3 & 3 \\
\hline & PB & 2 & 2 & 2 & 2 & 2 & 2 & 2 \\
\hline
\end{tabular}

Based on the result from $K_{p}^{\prime}, K_{d}^{\prime}, \alpha$ value, PID and FGPS parameter can be calculated using this equation:

$K_{p}=\left(K_{p \max }-K_{p \min }\right) K_{p}^{\prime}+K_{p \min }$

$K_{p}=\left(K_{p \max }-K_{p \min }\right) K_{p}{ }^{\prime}+K_{p \min }$

$K_{p}^{2} /\left(\alpha K_{d}\right)$

(Kp max, Kp min) and (Kd max, Kd min) is obtained from this following equation:

$$
\begin{aligned}
& K_{p \min }=0.32 \mathrm{Ku}, K_{p \max }=0.6 \mathrm{Ku} \\
& K_{d \min }=0.8 \mathrm{KuPu}, K_{d \max }=0.15 \mathrm{KuPu}
\end{aligned}
$$




\subsubsection{Indirect Field Oriented Control (IFOC)}

The principle of indirect field-oriented control system of an induction motor is that the d-q coordinate's reference frame is locked to the rotor flux vector, this results in a decoupling of the variables so that flux and torque can be separately controlled by stator direct-axis current ids, and quadratureaxis current iqs, respectively, like in the separately excited dc machine. To perform the alignment on a reference frame revolving with the rotor flux requires information on the modulus and position of the rotor flux [25].

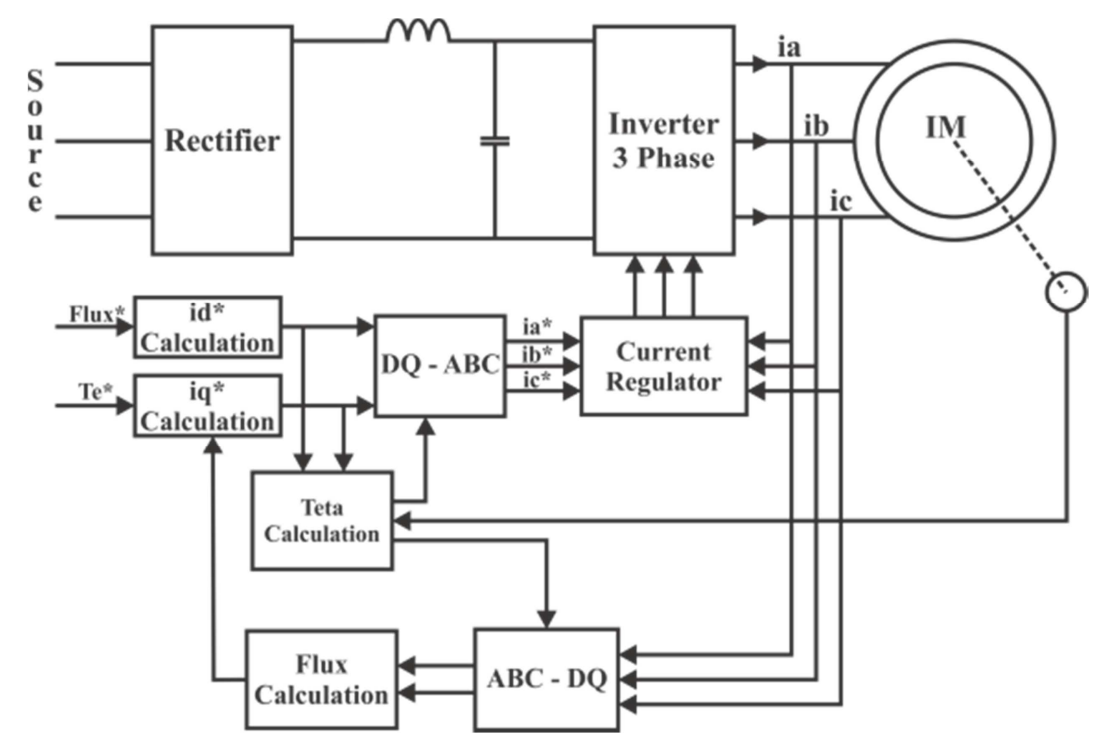

Figure 6. Block of diagram IFOC for Induction Motor

Rotor flux and torque can be separately controlled by stator direct-axis current (ids) and quadrature-axis currents (iqs) in sequence. Large quadratureaxis current reference (iqs*) can be calculated by reference torque $\mathrm{Te}^{*}$ using the following equation:

$$
i_{q s}^{*}=\frac{2}{3} * \frac{2}{P} * \frac{L_{r}}{L_{m}} * \frac{T_{e}^{*}}{\lambda_{r}^{*}}
$$

$\mathrm{Lr}$ is the rotor inductance, $\mathrm{Lm}$ is the mutual inductance and $\lambda \mathrm{r}$ is the flux linkage rotor estimation which is derived from this equation:

$$
\lambda_{r}=\frac{L_{m} i_{d s}}{1+\tau_{r} S}
$$

$\tau_{r}=\frac{L_{r}}{R_{r}}$ is the time constants of rotor. The number of direct-axis stator current reference $i_{q s}^{*}$ is based on the flux reference input $\lambda_{r}^{*}$ as follow:

$$
i_{d s}^{*}=\frac{\lambda^{*}}{L_{m}}
$$


The angle of flux rotor $\theta \mathrm{e}$ for coordinate transformation which is derived from rotation speed of rotor $\omega \mathrm{m}$ and slip speed $\omega$ sl calculation as follow:

$$
\theta_{e}=\int\left(\omega_{m}+\omega_{s l}\right) d t
$$

Slip speed is calculated from stator current reference $i_{q s}^{*}$ with this following motor parameter:

$$
\omega_{s l}=\frac{L_{m}}{\lambda_{r}^{*}} * \frac{R_{r}}{L_{r}} * i_{q s}^{*}
$$

Reference current iqs*danids* converted into a reference-phase flow ias* ,ibs*, ics* using the following equation (10) which will be the input current regulator. Then the flow regulator will process the reference phase current into a signal which triggers will control the inverter.

$$
\left[\begin{array}{l}
i a^{*} \\
i b^{*} \\
i c^{*}
\end{array}\right]=\left[\begin{array}{cc}
\cos \theta & -\sin \theta \\
\left(-\frac{1}{2} \cos \theta+\frac{\sqrt{3}}{2} \sin \theta\right) & \left(\frac{1}{2} \sin \theta+\frac{\sqrt{3}}{2} \cos \theta\right) \\
\left(-\frac{1}{2} \cos \theta-\frac{\sqrt{3}}{2} \sin \theta\right) & \left(\frac{1}{2} \sin \theta-\frac{\sqrt{3}}{2} \cos \theta\right)
\end{array}\right]\left[\begin{array}{l}
i d^{*} \\
i q^{*}
\end{array}\right]
$$

\subsection{Speed Control for three phase induction motor}

\subsubsection{Implemetationmodelling IFOC without Speed Control}

Based on block of diagram in Fig. 9, it is known by using IFOC method, flux and torque can be controlled separately. Flux will affect field current (ids*) and torque will affect torque current (iqs*). In this work, reference torque $\left(\mathrm{Te}^{*}\right)$ is given fixed value, while reference flux is got from block control output FGS-PID. Then Ids* and Iqs* are used for the calculation of Control Block of IFOC. The current sensor is used to know the motor current that is also used as calculation of IFOC block control. Output of IFOC block control is converted to be current $i_{a}{ }^{*}, i_{b}{ }^{*}, i_{c}{ }^{*}$ as input current regulator. Then, it will be processed to be a trigger signal that is used to control inverter as motor drive. Speed sensor is used to calculate the theta $(\theta)$ at coordinate system (direct axis - quadrature axis) that is used at IFOC block control, and also used for monitoring actual motor speed. Then, it is compared with speed reference so that it gets error value that is processed by PID controller as motor speed control to get speed reference. 


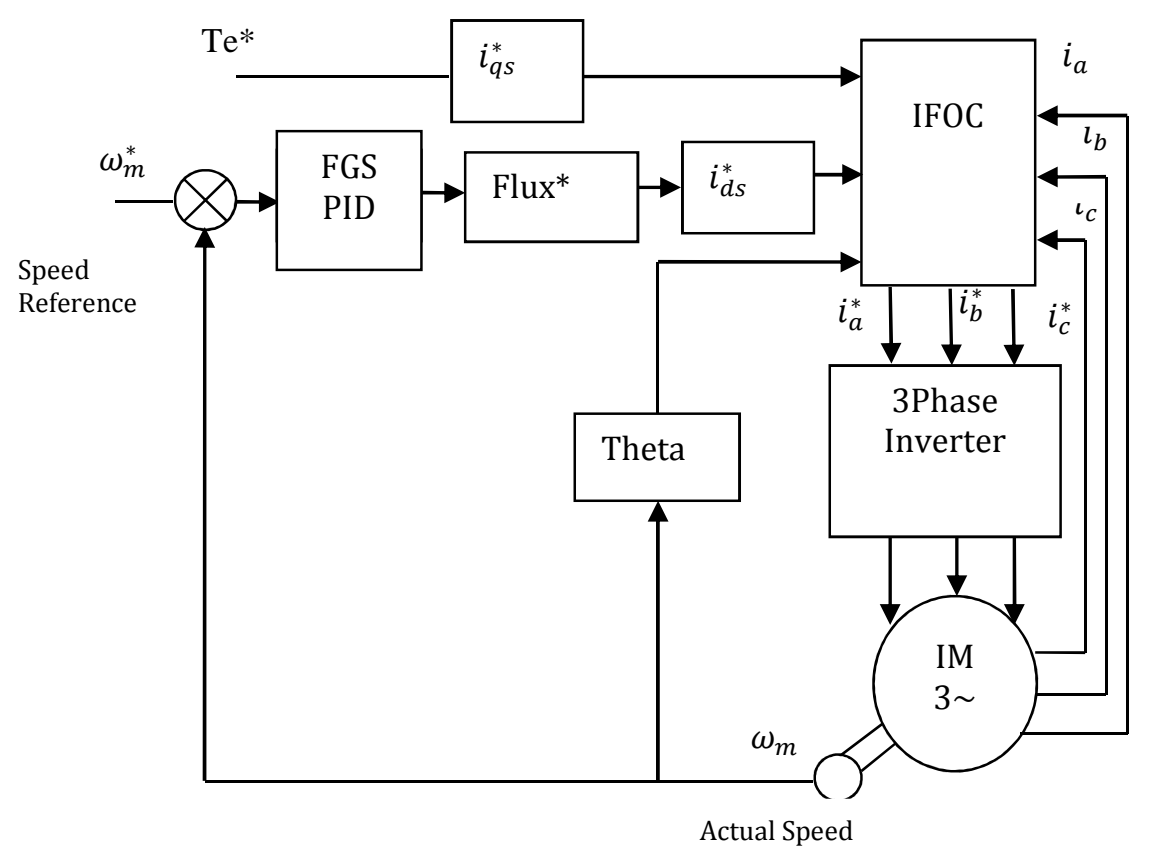

Figure 7. Block diagram of design system

In this paper proposed simulation model of three-phase induction motor with the implementation of Indirect Field Oriented Control (IFOC) system. Parameter of three-phase induction motors that was used in this simulation:

Table 5. Specification of induction motor

\begin{tabular}{|l|l|l|}
\hline No & Motor Parameter & \multicolumn{1}{|c|}{ Specification } \\
\hline 1 & Voltage & 400 volt \\
\hline 2 & Power & $7.5 \mathrm{kw}$ \\
\hline 3 & Frequency & $50 \mathrm{~Hz}$ \\
\hline 4 & Speed & $1440 \mathrm{Rpm}$ \\
\hline 5 & Rotor Type & Squirrel Cage \\
\hline 6 & Rotor Resistance & $0.7402 \Omega$ \\
\hline 7 & Stator Resistance & $0.7384 \Omega$ \\
\hline 8 & Rotor Inductance & $0.003045 \mathrm{H}$ \\
\hline 9 & Stator Inductance & $0.003045 \mathrm{H}$ \\
\hline 10 & Mutual Inductance & $0.1241 \mathrm{H}$ \\
\hline 11 & Pole & 2 \\
\hline 12 & Inertia & $0.0343 \mathrm{Kg}$ \\
\hline
\end{tabular}

The system IFOC the transformation stationer frame into rotational frame using Clark and Park Transformation. Clark transformation is used to modify three-phase stationary (ia, ib, ic) to be two-phase stationary (i $\alpha, i \beta)$. While, Park Transformation modify two-phase stationary to the two phase rotational (id, iq) that was illustrated in Fig. 10. 




Figure 8. Model of Indirect Field Oriented Control (IFOC)

\subsubsection{Design of Fuzzy Gain Scheduling PID}

The design of Fuzzy scheduler for FGS-PID using two input values, those are error value and delta error value. The output from the result of scheduler fuzzy is also used to this system based on gain value as the PID control basic calculation. Gain value is determined by scheduling process which can be used to obtain the best and the compatible gain from the operating condition. Scheduling system is also used to determine gain value when there is modification parameter in control system. Fuzzy gain scheduler model of this system is ilustrated in Fig.9.

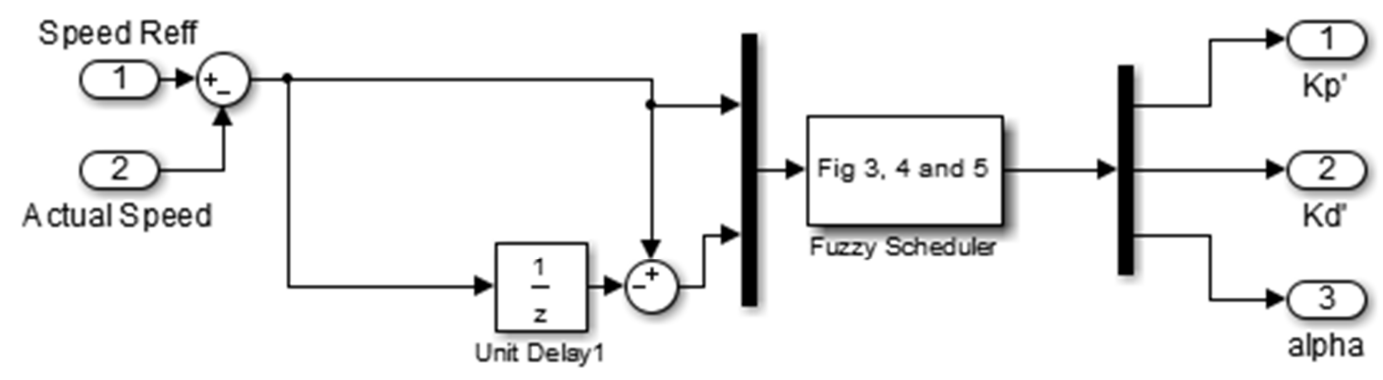

Figure 9.Block of diagram fuzzy gain scheduler

The modification parameter or disturbance which is occured in control system can be caused trancient condition and required addition time to repair the performance from the control system in getting suitable result with setpoint. This condition is influenced with the value of gain which isn't suitable to the PID system and also reduce its performance. Using the compatible gain based on scheduling system can be repaired the response from the output of control system which is still suitable with expected result although it has modification parameters. 


\section{EXPERIMENT RESULT AND ANALYSIS}

\subsection{Simulation Result IFOC without Speed Control}

The simulation system of IFOC without speed control of three-phase induction motor using IFOC, was depicted in Fig. 10.

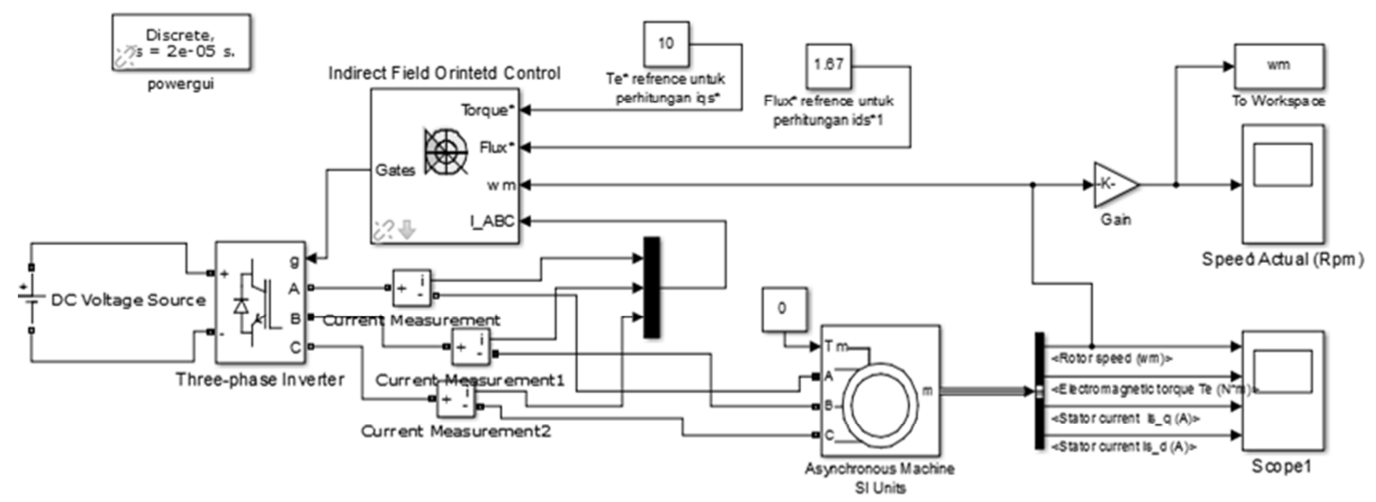

Figure 10.Simulationspeed control of three phase induction motor using IFOC

The output of response speed control using IFOCcan be got speed motorin $350 \mathrm{Rpm}, 400 \mathrm{Rpm}$, and $450 \mathrm{Rpmthat}$ was ilustrated in the following below:.

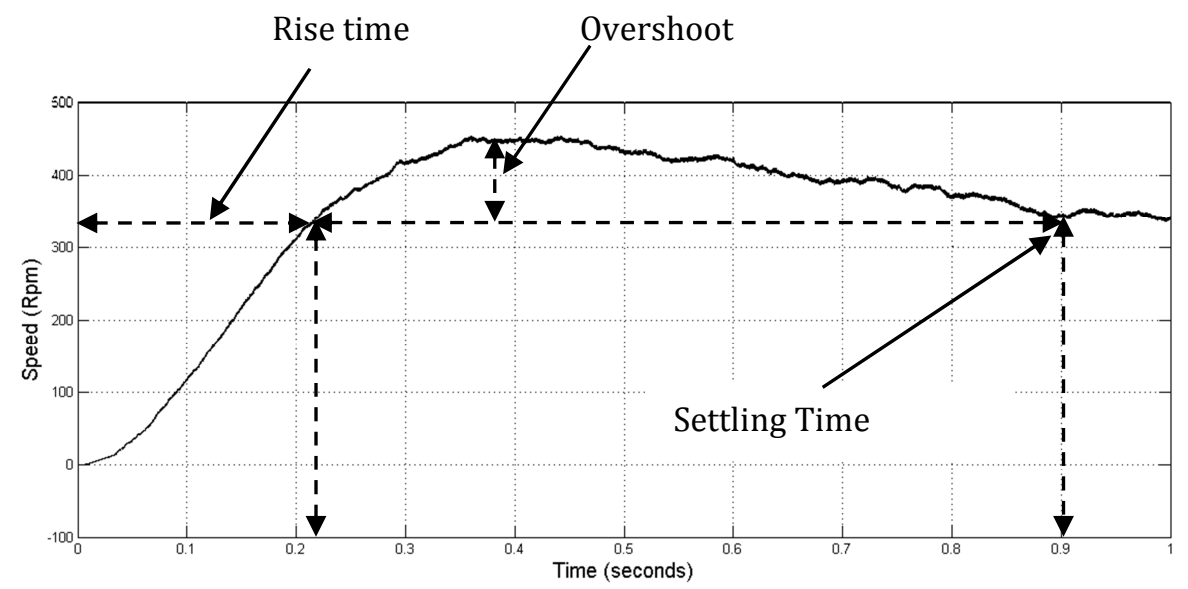

Figure 11.Simulation result speed controlwithIFOC on the speed motor $350 \mathrm{Rpm}$

The simulation result(Fig.11) can see the output response system. The rise time value to get speed in $350 \mathrm{Rpm}$ was 0.23 second. The maximum overshoot is $28 \%$, and time settling 0.89 second before steady speedcondition. 


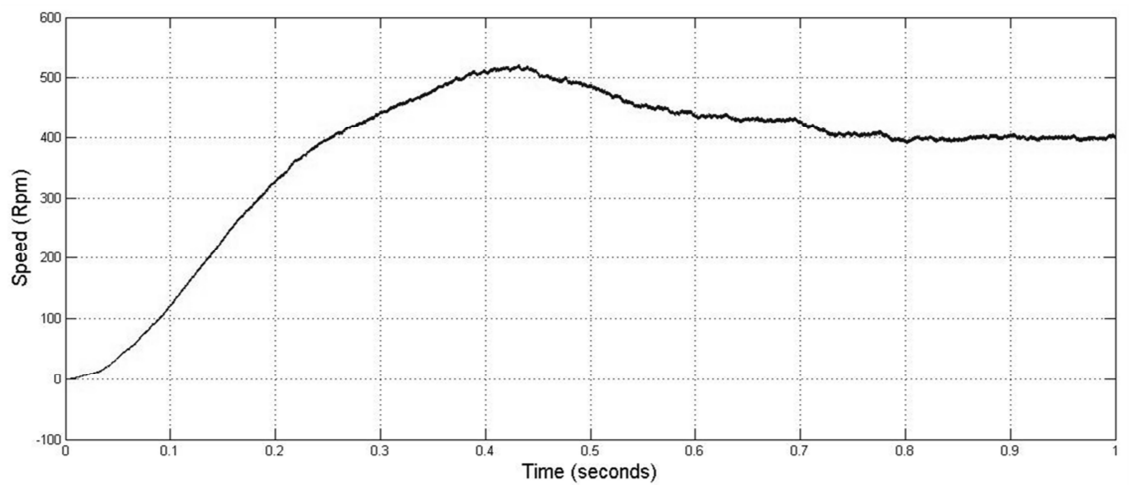

Figure 12.Simulation result speed control with IFOC on the speed motor $400 \mathrm{Rpm}$

While, the number ofrise time to get speed 400 Rpm was needed 0.256 second that has maximum overshoot $29 \%$, and time settling 0.74 second before condition steady speed, depicted in Fig. 12.

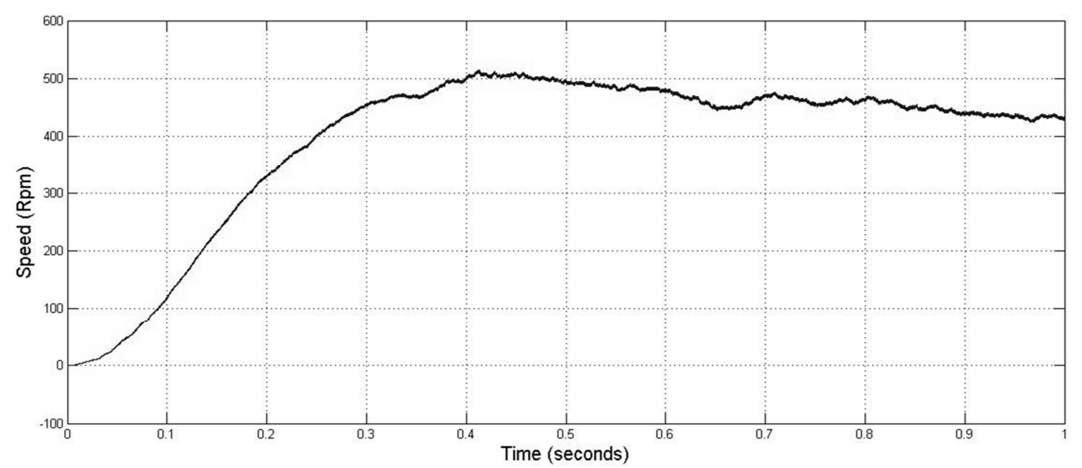

Figure 13.Simulation result speed control with IFOC on the speed motor $450 \mathrm{Rpm}$

In Fig.13 speed 450 Rpm was needed 0.23 second rise time, $28 \%$ maximum overshoot, and time settling 0.93 second before condition steady speed.

\subsection{Simulation Result IFOC with Speed Control FGS-PID}

The Fuzzy gain scheduling -PID (FGS-PID) have a structure similar to ideal PID controllers, but their parameters are adapted online based parameter estimation and prediction when there was modification parameter on control process. FGS-PID will perform the process scheduling on the gain that most affect the performance of PID control when there is a modification parameter so as to maintain optimum control response. Fuzzy Logic will perform online tuning to obtain a suitable the gain in accordance with the prescribed range without having to change the gain-gain others. The simulation of IFOC that used speed control FGS-PID for three-phase induction motor, ilustrated in Fig. 14. 


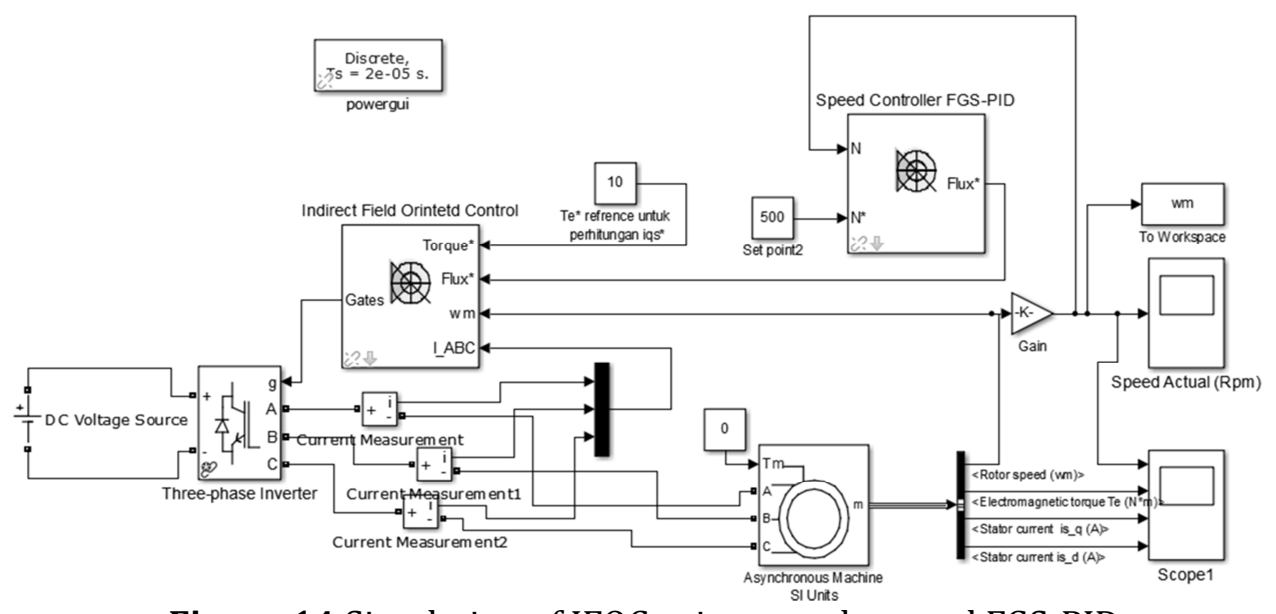

Figure 14.Simulation of IFOC using speed control FGS-PID

In Fig. 15, showsthe diagram block of speed control FGS-PID for three-phase induction motor based on IFOC.

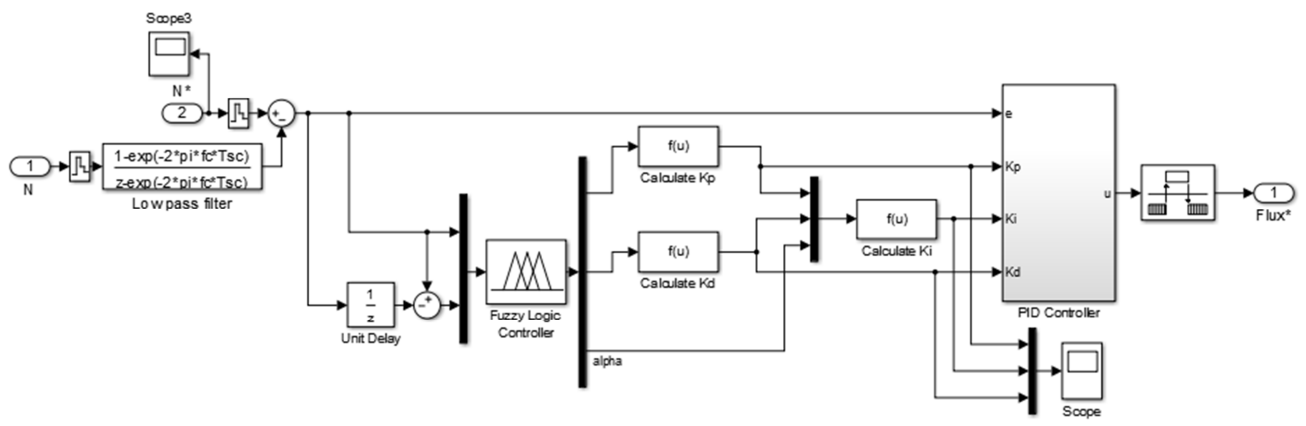

Figure 15.Block of Speed ControlIFOC using FGS-PID

The proposed sytem is tested by dynamic of speed or position modification from setpoint (reference speed) with 0 seconds to 0.01 seconds sampling tme. The first condition: we assumed $300 \mathrm{Rpm}$ setpoint, and after the simulation is running at 0.05 seconds in steady state condition,will be increased the setpoint up to $600 \mathrm{Rpm}$ and 0.1 seconds steady state condition. The maximum set point limitation is based on operation fields from scheduling which is $1000 \mathrm{Rpm}$. The simulation results is observed and analyzed the performance of induction motor in transient contidition involve rise time, overshoot, undershoot and settling time. 


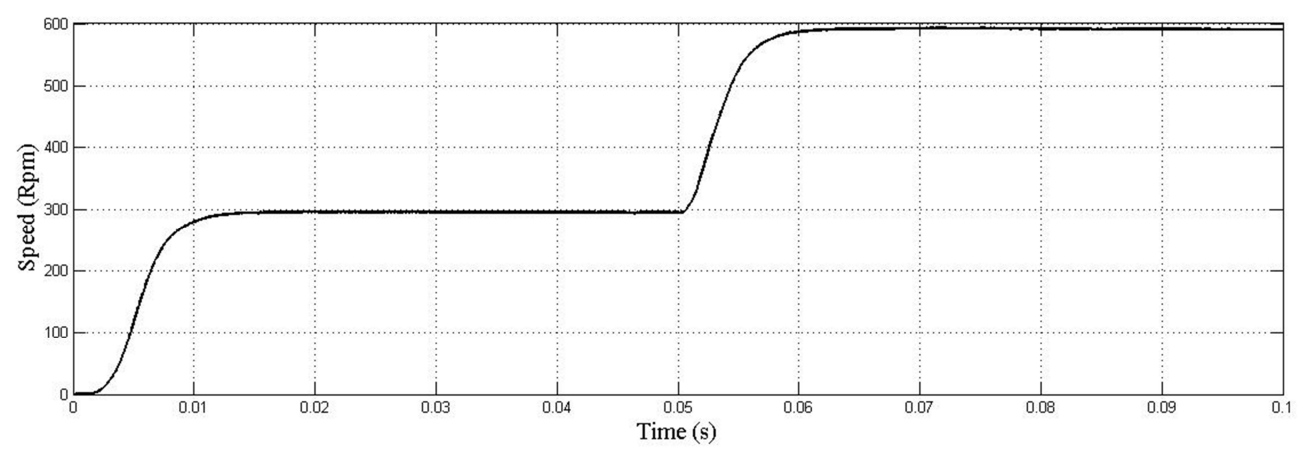

Figure 16.Simulation result FGS-PID at speed modification $300 \mathrm{Rpm}-600 \mathrm{Rpm}$

The performance result from FGS-PID control for three phase induction motor of IFOC based is using set point variable as shown in Fig.20. The sytem responses can be analyzed or observed with 0.1 seconds sampling time as follows:

Table 6.Result observation transien condition at speed control using FGS-PID

\begin{tabular}{|l|c|c|}
\hline \multirow{2}{*}{} & \multicolumn{2}{|c|}{ Speed (Rpm) } \\
\cline { 2 - 3 } & 300 & 600 \\
\hline Rise time (s) & 0.0135 & 0.0132 \\
\hline Overshoot (\%) & 0 & 0 \\
\hline Undershoot (\%) & 0 & 0 \\
\hline Settling time (s) & 0.014 & 0.0143 \\
\hline
\end{tabular}

The next condition, we declared $400 \mathrm{Rpm}$ setpoint and 0.05 seconds steady state condition at the runned simulation. It will be reduced up to $200 \mathrm{Rpm}$ setpoint and 0.1 seconds in steady state condition. For the last, the setpoint is set in $150 \mathrm{Rpm}$ and 0.1 seconds steady state condition.



Figure 17.Simulation result FGS-PID at speed modification 400 Rpm - 200 Rpm

The result responses sytem from second condition of FGS-PID can see in Fig.17 and it analyzed or observed show in table 7: 
Table 7.Secondresult observation transien condition using speed control FGS-PID

\begin{tabular}{|l|c|c|}
\hline \multirow{2}{*}{} & \multicolumn{2}{|c|}{ Speed (Rpm) } \\
\cline { 2 - 3 } & 400 & 200 \\
\hline Rise time (s) & 0.017 & 0.0085 \\
\hline Overshoot (\%) & 0 & 0 \\
\hline Undershoot (\%) & 0 & 0 \\
\hline Settling time (s) & 0.017 & 0.0173 \\
\hline
\end{tabular}

From the observation above is known that FGS-PID control has a better response can be solve the problem in transient condition to get steady state

condition only takes less than 0.01 seconds without getting overshoot and undershoot.

\subsection{The comparison proposed FGS-PID with other speed control}

FGS-PID control are proposed to be used to improve transient conditions in implementation IFOC for induction motors to achieve steady state when modified parameters.By performing IFOC methods for induction motor can be to modify characteristic nonlinear similarly of DC motor which is expected to control systems designed to obtain optimal results because the process is controlled in linear conditions.Some control used on an induction motor, majority want to get good result to achieve setpoint so ignore the transient condition other. The performance result from the comparison between FGSPID, PID-Zn and FuzzyBackstepping for three phase induction motor of IFOC based is using set point variable as shown in Fig.18. The sytem responses can be analyzed and observed with 0.1 seconds sampling time as follows:

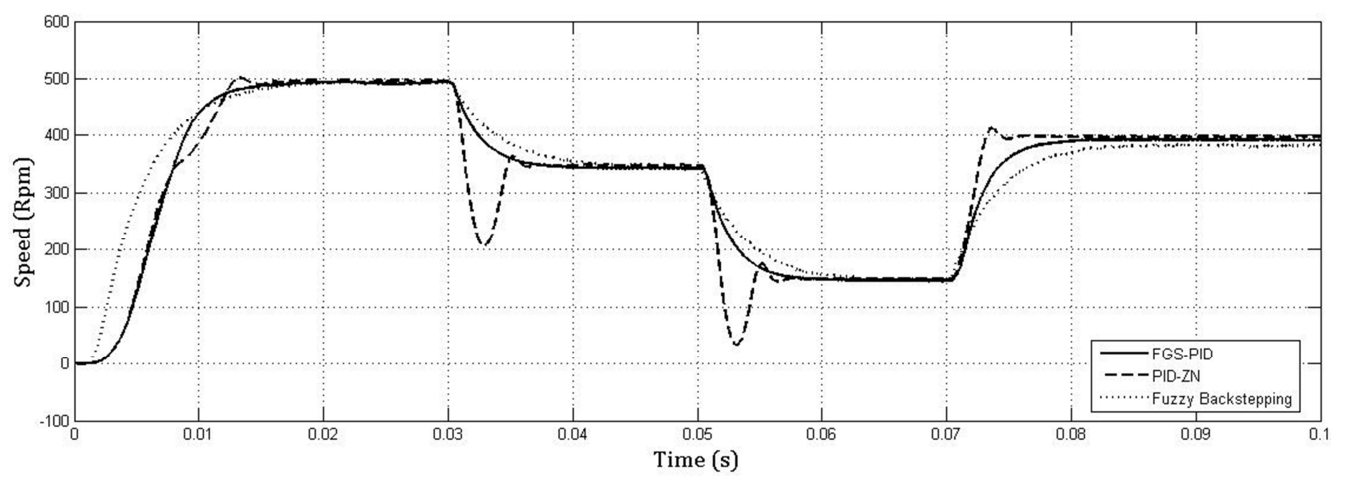

Figure 18. Comparison between FGS-PID, PID-ZN, and Fuzzy Backstepping at speed of dynamic

The comparison result is observed respon induction motor in transient condition for speed of dynamic, shown on the table 8, 9, and 10. 
Table 8.Theresult observation transien condition on speed control FGS-PID

\begin{tabular}{|c|c|c|c|c|}
\hline \multirow{2}{*}{} & \multicolumn{4}{|c|}{ FGS-PID } \\
\cline { 2 - 5 } & 500 & 350 & 150 & 400 \\
\cline { 2 - 5 } & 0.015 & 0.006 & 0.001 & 0.0085 \\
\hline Rise Time (s) & 0 & 0 & 0 & 0 \\
\hline Overshoot (\%) & 0 & 0 & 0 & 0 \\
\hline Undershoot (\%) & 0.0173 & 0.0010 & 0.0011 & 0.0014 \\
\hline Settling Time (S) & 0.014 &
\end{tabular}

Table 9.The result observation transien condition on speed control PID-ZN

\begin{tabular}{|c|c|c|c|c|}
\hline \multirow{2}{*}{} & \multicolumn{4}{|c|}{ PID-ZN } \\
\cline { 2 - 5 } & \multicolumn{4}{|c|}{ Speed (Rpm) } \\
\cline { 2 - 5 } & 500 & 350 & 150 & 400 \\
\hline Rise Time (s) & 0.013 & 0.0015 & 0.005 & 0.0035 \\
\hline Overshoot (\%) & 0.11 & 3.42 & 15.2 & 0.302 \\
\hline Undershoot (\%) & 2.04 & 40.71 & 76.9 & 1.56 \\
\hline Settling Time (S) & 0.018 & 0.007 & 0.0075 & 0.0095 \\
\hline
\end{tabular}

Table 10.The result observation transien condition on speed control

\begin{tabular}{|c|c|c|c|c|}
\multicolumn{4}{c|}{ Fuzzy-Backstepping } \\
\cline { 2 - 5 } & \multicolumn{4}{|c|}{ Fuzzy-Backstepping } \\
\cline { 2 - 5 } & 500 & 350 & 150 & 400 \\
\hline Rise Time (s) & 0.0185 & 0.0095 & 0.0093 & 0.0105 \\
\hline Overshoot (\%) & 0 & 0 & 0 & 0 \\
\hline Undershoot (\%) & 0 & 0 & 0 & 0 \\
\hline Settling Time (S) & 0.0195 & 0.0035 & 0.0014 & 0.0016 \\
\hline
\end{tabular}

From the comparison result of the control system in Fig. 18, can be observed the transient condition result involved rise time, overshoot undershoot and settling time. The result shows the better performance from the proposed method using FGS-PID in modification parameter which is verifed by the result from Table 7-10. The longest time for modification only needs 0.0014 seconds to achieve steady condition without overshoot and undershoot condition. While using PID-ZN take 0.007 seconds to reach steady condition and the Fuzzy-Backstepping need 0.0014 seconds. It proves that the proposed method has better performance in modification parameter. 


\subsection{Scheduler of parameter gain on PID control}

The results of the scheduling gain of PID parameters are presented below:

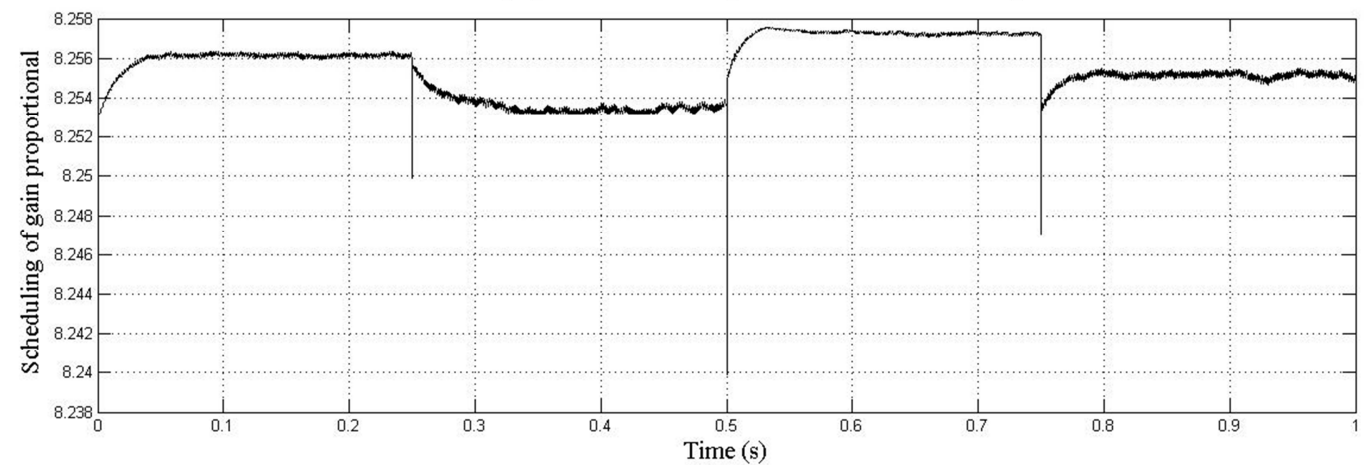

Figure 25.Scheduler of gain proportional for the control of dynamic speed 250 Rpm, 500 Rpm, 100 Rpm, and 300 Rpm

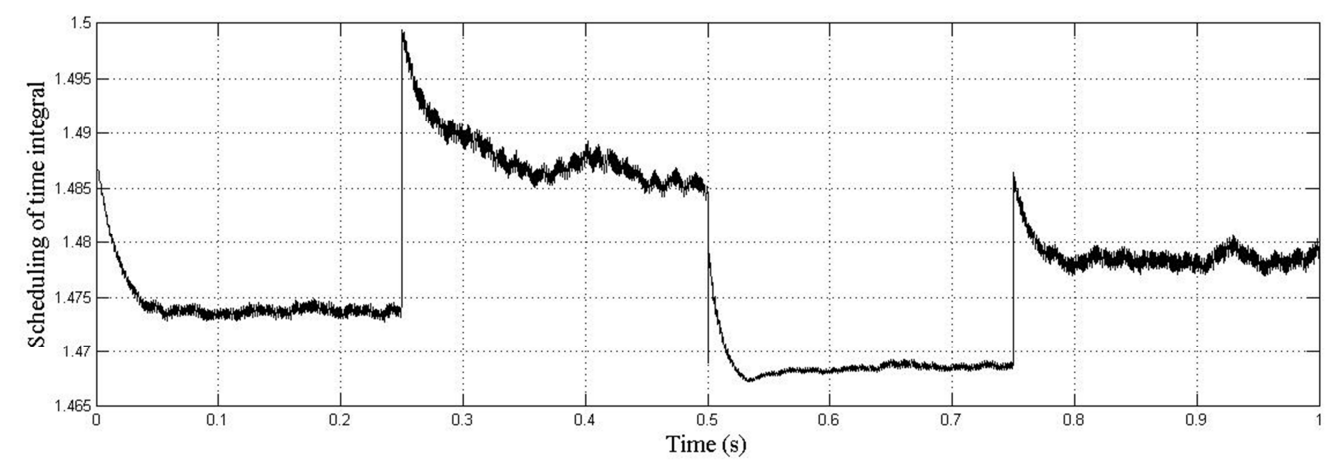

Figure 26.Scheduler of time constant integral for the control of dynamic speed $250 \mathrm{Rpm}, 500 \mathrm{Rpm}, 100 \mathrm{Rpm}$, and $300 \mathrm{Rpm}$

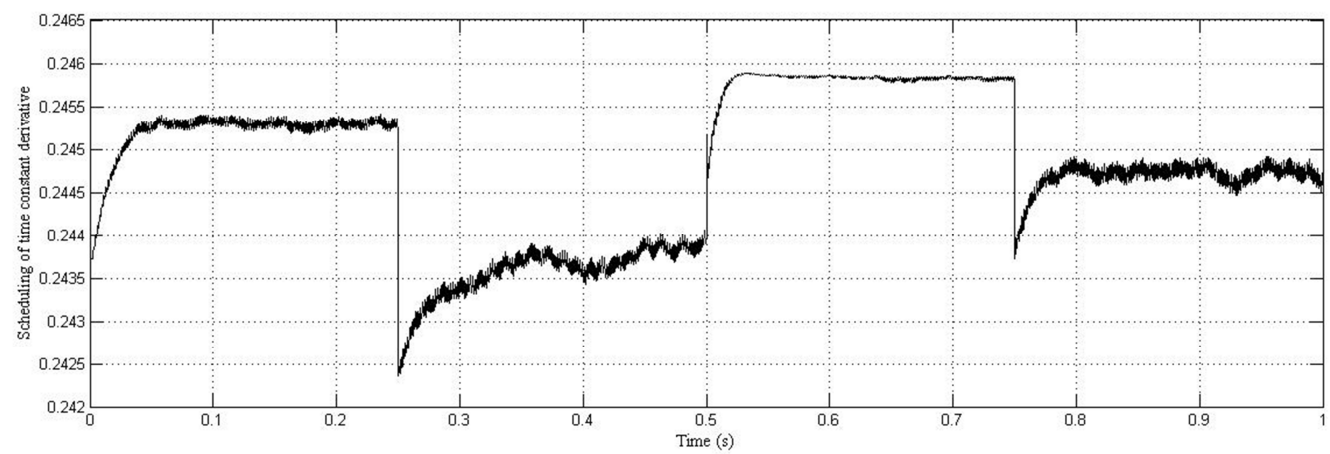

Figure 27.Scheduler of time constant derivative for the control of dynamic speed 250 Rpm, 500 Rpm, 100 Rpm, and 300 Rpm 
On the graph in Fig 25, Fig 26, and Fig 27,it can be observed that scheduling gain process will be performed when control process parameter is modified, so it still gets a good result. From the results above with a sampling time of 0 1 second, it is observed on performed scheduling process. At time $0-0.25$ second with setpoint $250 \mathrm{rpm}$, then obtained value gain of proportional (Kp) is 8,256, time integral constant (Ti) is at 1.474, and time derivative constant (Td) is 0.2455 . When there is a modifiedsetpoint to be $500 \mathrm{rpm}$ at $0.25-0.5$ seconds,it is performed the scheduling again to get a suitable value.(Kp) is 8.2537, (Ti)is 1.486, and (Td)is 0.2437. And then, when setpointis100 Rpm at time $0.5-0.75$ second, the result of scheduling (Kp)is 8.2577, (Ti)is 1.478, and (Td)is 0.2457 . When the last condition, setpointis $300 \mathrm{Rpm}$ at time 0.75 1 second, (Kp)is 8.255, (Ti)is 1.478, and (Td)is 0.24457.

\section{CONCLUSION}

Design of proposed FGS-PID in the three-phase induction motor speed control using IFOC methods can provide good results. It is verified with testing a reliability of control system on dynamic speed. With this method of observation in transient conditions (involve rise time, overshoot, undershoot, and settling time) it can be knownthat the performance of the control system is in good condition although the parameters of process control is modified, because it has a fast response below 0.0004 second to achieve a steady state condition without getting overshoot and undershoot. The other advantage of FGS-PID based on IFOC in induction motors is, it can have linearization characteristic of the motor, so it can be easy to control as DC motor. Thus, when getting linear conditions, FGS-PID control can more easily generate optimum performance even though applied to condition of fluctuation.

\section{ACKNOWLEDGEMENTS}

The first I extend thanks to "ALLAH SWT" always give love and help me in researcher, secondly my family is always pray for me and then i thanks to "Kementerian Riset, Teknologi dan Pendidikan Tinggi Republik Indonesia" which was approve the scholarship freshgraduate program in Study Program of Applied Master's Degree Electrical Engineering at Politeknik Elektronika Negeri Surabaya and also the all friend in "Tanggul Islamic Centre" who have helped this research better.

\section{REFERENCE}

[1] J.P. Hautier J.P. Caron, Modeling and Control of Induction Machine, Technip ed., 1995.

[2] I.K. Bousserhane, A. Hazzab, M. Rahli, B. Mazari, and M. Kamli "OPTIMAL FUZZY GAINS SCHEDULING OF PI CONTROLLER FOR INDUCTION MOTOR SPEED CONTROL ," Acta Electrotechnica et Informatica , vol. 7, no. $1,2007$.

[3] R.D.Lorenz and D.B. Lawson, "A Simplified Approach to Continuous OnLine Tuning of Field-Oriented Induction Machine Drives," IEEE Trans. On 
Industry application, vol. 26, no. 3, may 1990.

[4] L. Baghli, "Contribution to Induction Machine Control: Using Fuzzy Logic, Neural Networks and Genetic Algorithms," Henri Poincare University, Doctoral Thesis 1999.

[5] M.A. Ouhrouche, C. Volet "Simulation of a Direct Field-Oriented Controller for an Induction Motor Using Matlab/Simulink Software Package," in IASTED, USA, 2000.

[6] Salah Eddine Rezgui and Hocine Benalla, "High Performance Controllers for Speed and Position Induction Motor Drive Using New Reaching Law," International Journal of Instrumentation and Control Systems (IJICS), pp. 31-46, 2011.

[7] Zhen-Yu Zhao, Masayoshi Tomizuka, and Satoru Isaka, "Fuzzy Gain Scheduling of PID Controllers," IEEE Transactions On Systems, pp. 1392 1398, 1993.

[8] Kuo. B.C, Automatic Control System, 5th ed. Englewood Cliffs: Prentice Hall, 1987.

[9] M.J. Rabins, and D.M, Auslander Y. Takahasi, Control and dynamic systems. Menlo park: Addison Wesly, 1970.

[10] hang H.S and J Gertler, "An instability indicator for expert control," IEEE, vol. 6, pp. 34-42, 1986.

[11] C.C Hang, and W. K. Ho K.J. Astrom, "Refinements of the Ziegler Nichols tuning formula," in IEE, Pt.D, 1991, pp. 111-118.

[12] M. Sugeno, Industrial aplications of fuzzy control. Amsterdam, Netherland: North-Holland, 1985.

[13] II Munadhif , Aulia Siti. A, dan A. Agus M, "Perancangan sistem kendali kestabilan rolling kapal perang kelas sigma saat bermanuver menggunakan Fuzzy Gain Schedulling-PID, Tesis, Institut Teknologi Sepuluh Nopember, (Surabaya),2015"

[14] Kuo. B.C, Automatic Control System, 5th ed. Englewood Cliffs: Prentice Hall, 1987.

[15] Chang H.S and J Gertler, "An instability indicator for expert control," IEEE, vol. 6, pp. 34-42, 1986.

[16] Zigler. J. G. and N. B. Nichols, "Optimum setting for automatic controllers," Trans ASME, vol. 64, pp. 759-768, 1942.

[17] Gawthrop P. J and P.E. Nomikos, "Automatic tuning of commercial PID controllers for single-loop and multiloop aplications," IEEE Control Sys. Mag, vol. 10, pp. 34-42, 1990.

[18] S. Omatu, and H. Ishihara T. Yamamoto, "A construction of self tuning PID control system," Trans.SICE. Japan, vol. 25, pp. 39-45, 1989.

[19] C.C. Lee, "Fuzzy logic in control system: Fuzzy logic controller part 1," IEEE Trans. Sys Man cybern, vol. SMC-20, pp. 404-418, 1990. 
[20] T.J Procyk and E. H. Mamdani, "A linguistic self-organizing process controller," Automatica, vol. 15, pp. 15-30, 19791.

[21] M. Sugeno, Industrial aplications of fuzzy control. Amsterdam, Netherland: North-Holland, 1985.

[22] Takagi. T and Sugeno. M, "Fuzzy identification of systems and its aplications to modeling and control," IEE Trans, vol. SMC-15, pp. 116132, 1985.

[23] Arun Kumar R, "Indirect Field Oriented Control of Induction Motor Using Fuzzy Logic," in ResearchGate, 2012.

[24] Era Purwanto , Gigih Prabowo, Endra Wahyono, dan M. Machmud Rifadil, "Pengembangan Model Motor Induksi sebagai Penggerak Mobil Listrik dengan Menggunakan Metode Vektor Kontrol," Jurnal Ilmiah ELITE Elektro (Institut Teknologi Sepuluh Nopember Surabaya), pp. 6772, 2011.

[25] Rizana Fauzi , Dedid Cahya Happyanto, and Indra Adji Sulistijono, "Fast Respon Three Phase Induction Motor Using Indirect Field Oriented Control (IFOC) Based On Fuzzy-PI," IES, 2014.

[26] Gagan Singh Gurmeet Singh, "Modeling and Simulation of Indirect Field Oriented Control of Three Phase Induction Motor using Fuzzy Logic Control," International Journal of Engineering Research \& Technology (IJERT), vol. 3, no. 8, pp. 1126-1130, August 2014.

[27] DR.V. Rajasekaran, DR.I.Gerald C, N. Panner S M. Arul Prasanna, "Modeling, Analysis and IFO COntrol Method For CSI FED 3 Phase Induction Motor Drive," Journal of Theoritical and Applied Information Technology, pp. 444-451, 2014.

[28] Bilal Akin, State Estimation Technique For Speed Sensorless Field Oriented Control of Induction Motors.: School of Natural and Applied Sciences, 2013.

[29] Ananda kumar Akkaraapaka and Dherendra singh, "The IFOC Based Speed Control of Induction Motor fed by A High Performance Z-Source Inverter," IEEE, 2014.

[30] Abdelkader M, Yessema B M'hamed Chebre, "Speed Control of Induction Motor Using Genetic Algorithm-based PI Controller," Acta Polytechnica Hungarica, pp. 141-153, 2011. 